PESHAWAR JOURNAL OF PSYCHOLOGY AND BEHAVIORAL SCIENCES, 2018, VOL. 4, NO. 2, 193-202

\title{
Relationship between Social Media Marketing and Consumer Buying Behavior
}

\author{
Syed Muhammad Ather ${ }^{1}$, Naimat Ullah Khan ${ }^{2}$, \\ Faizanur Rehman ${ }^{3}$ \\ University of Peshawar \\ and
}

\section{Lubna Nazneen ${ }^{4}$ \\ Islamia College Peshawar}

The social media has become an integral part of our lives with the introduction of 3G, 4G technology in Pakistan it has become possible for people to stay connected from anywhere any time. The purpose of this study was to find out that if any relationship between social media marketing and consumer buying behavior exist if their existence affected each other in any significant way. For this purpose an online survey was conducted and 100 people responded who were active users of social media in Peshawar, a structured questionnaire was designed to collect information from the respondents. Distribution of the questionnaire was done by emailing its link and posting it on different social media sites. The research findings and results confirmed that there is a positive relationship between social media marketing and consumer buying behavior, as well as that social media can be used as an effective marketing tool.

Keywords: social media, consumer buying behavior, social networking sites and marketing.

Social media also known as web 2.0 has changed how people interact with each other as well as how they get their information. We live

\footnotetext{
${ }^{1}$ Institute of Management Studies, University of Peshawar

${ }^{2}$ Institute of Management Studies, University of Peshawar

${ }^{3}$ Institute of Management Studies, University of Peshawar

${ }^{4}$ Lecturer, Department of Psychology, Islamia College Peshawar
}

ISSN 2415-6779 EISSN 2518-4474

https://doi.org/10.32879/picp.2018.4.2.193

www.pjpbsicp.com 
in a brave new world in which technology is making leaps forward and daily new software's and apps are released that enhance how things are done. Social media has become the go to medium on how people express themselves to the world as well as how they communicate with each other. In such changing times many opportunities arise one of which is using this mode of communication to directly interact with the customers in such a way which has not been possible before which gave birth to social media marketing. The appearance of social media has made a new dimension which gives a network of connections. There are huge opportunities for businesses to strike the trends, and the customers are put forth in the business world due to social media. Based on the findings from McKinsey (2011), smart phones, websites of social media, customer devices have enabled to add information, by a number a people all over the globe. When companies interact with individuals for their business they generate a huge amount of digital exhaust data as a byproduct of some other tasks or functions. While searching the commerce websites, social media forums, sales emails, it appears that companies have moved their marketing techniques to the internet because of its approach to the targeted segment of market and finances.

The use of the word web 2.0 and social media has been used interchangeably by different researchers (Kaplan \& Haenlein 2009, Safko $\&$ Brake 2009), though these two terms are close to each other but they are not synonymous. The operational definition of web 2.0 which was given by Tim O' Riley (2006), who is the founder of O' Riley media, brought a business revolution in the computer industry. He also provided the relation between web 2.0 and "harnessing of collective intelligence". But the social media's universal definition is still awaited; it is now defined as transformation and combination of evolution of modern media, (Solis 2010) which is the main purpose of social media. Dann \& Dann (2011) give a framework of social media components like social interaction, content and communication media which has enhanced communication flow. According to Kaplan \& Haenlein (2009) the activities, practices and behavior among people who share opinion, Information and knowledge using verbal media are referred as social media. The current of communication is two way process because social media as it is open to participation and feedback (Mayfield, 2008) Since social media is a powerful medium the separate entities are occupied with the contents on the internet and vice versa. Social media, a user centered which facilitates the process of sharing, editing, commenting and creating. According to 
Solice (2007), it is right to say that social media is related to the democracy of content.

\section{Types of Social Media}

Social networking sites (SNSs), bookmarking sites and social news, media sharing site, web journals, micro blogging are the major types of social media. Long range informal communication Sites (SNSs) are junctures where people can interface with each other, for occasion MySpace \& Facebook. Long range interpersonal communication destinations, It is stated by Weinberg $(2009,149)$, "are non-specific terms for locales that are utilized to associate clients with comparable foundations and interests". Social Bookmarking locales and Social News destinations for cases like Reddit, Scoop and Digg are really comparable and are particularly in the form of online group (Zarrella 2010, 103.) Media-Sharing locales (e.g. Flicker and YouTube) are channels where people can store, share and transfer their sight and sound records, for example photographs, music and recordings, with various clients. One of the real gears of these media-sharing destinations must be emphasized is the tag. "A tag is a word appointed to a bit of substance that depicts it", which suggests that establishments need to identify and understand the importance of the pursuit words on the web search tools (Zarrella, 2010, 81).A web journal is an online journal or diary which is as allude to a kind of substance administration framework (CMS), commonly kept up by people or aggregates, and highlighted discourse and feelings for a bigger gathering of crowd (Safko\& Brake 2009). Micro blogging allows customers to send their messages through texts, messages through their cellphones to different sites e.g. twitter, skyrocketed in 2006 is one of the original and powerful micro blogs which has more than 140 million customers starting 2012 which handles more than 1.6 billion inquires everyday (Twitter, 2011).

\section{Social media and marketing}

Online network marketing is a broad term which provides and depicts the social networking levels as an advertising device. Weinberg (2009) emphasized that social media is one of the ways to engage people in order to move forward their products through social media to take benefit of a bigger group which might not have been reachable by customary promoting mediums. 
Social web is a standard medium through which people share their thoughts, can post comments on different market articles and can also publicize their products, can also give response to different marketing campaigns which are initiated through online surveys (Weber 2009).

\section{Social media: The new mentality}

Gaining better position in social media marketing, those who use conventional marketing approaches are required to change their mentality. Social media has totally changed the approach of formation of the segments in implementation of the master plan of the marketing. Instead of focusing on demographics like gender, age and income etc. we should focus on the apparent behavioral preferences of each group, and it can be studied through their likes and dislikes which they show for different market products through social media (Weber, 2009)

Numerous advertising specialists (Weber 2009; Weinberg 2009; Drury 2008; Mayfield 2008) have constantly emphasized that promoting online networking is to promote trading of thoughts and discernments that can make marketing possible by a two-way process between brands and groups of individuals. As a rule, material is considered to be the core element in achieving a viable advertising by making use of online networking. Difficulties have been faced by companies producing unique material and to give a better exposure and popularity to a product through social media some out brilliant material is needed to be discovered (Jacobs, 2013). Drury (2008) opposed that utilizing online networking specifically, the material of endorsing and marking should be provided with a significant worth including material that is more about buyer, instead of brash item position. When organizations help their customers through online networking channels, at that stage,it may assemble a long haul relationship that might move and influence the brand mindfulness and development (Young Entrepreneur Council, 2012)

\section{Social media and consumer}

Online networking is very important in giving the customers a medium of expression. The possible parts required in the customer's choice making process are their nature and some apparent or distinct component in different online channels. The rationale is that online networking is crucial in today's world (Smith \& Zook 2011; Zarrella 2010; Weber 2009; Weinberg 2009). It is important to know how customers are affected by 
internet use and to recognize how their online preferences effect their buying behavior for different products (Fennis \& Stroebe, 2011). Similarly to collect a valid data about consumer preferences through social media is also a challenge, because it is sometimes possible that unnecessary variables contaminate the true data. (Silverman, 2001). Almost all social media play important role in receiving, exchanging and dissemination of unlimited information. If the exchange of information through social media does not impact organization to get closer to each other and to their goals, denial, distortion and miss interpretation of messages can be considered as the possible drawbacks in exchange process(Smith \& Zook, 2011).

Social media has become main mode of communication for both male and female populations in Peshawar. In near future social media will become main line stream mode of interaction as compared to traditional media. The finding of this research will provide the marketers as well as future researchers about whether or not social media marketing in an effective tool to be used in order to effect consumers buying behavior or not in the area of Peshawar. This can open ways for the promotion of market products through social media.

\section{Objectives of the study}

- To understand the impact of social media marketing on consumer buying behavior.

- To study and to provide the possible implications of the social media marketing on consumer buying behavior in Peshawar.

\section{Hypothesis}

- Social media marketing will have a significant impact on consumer buying behavior in Peshawar.

\section{Method}

\section{Sample}

The sample for this research comprised of one hundred customers selected from Peshawar through convenient sampling technique.

\section{Instrument}

The instrument used for the data collection in this research is questionnaire. The questionnaire was designed by the researcher. Cronbach 
alpha was found to be .58 and the questionnaire consisted of 29 questions with close ended items. A likert type scale was used to quantify the responses. In the first part of the questionnaire the demographic questions were asked including gender and age. The $2^{\text {nd }}$ part consisted of items related to the main variables in the study.

\section{Procedure}

The method of distributing the questionnaire was done through emails its link and posting it on different social media sites and asking people of Peshawar to fill it and thus submitting their responses online. Improperly filled questionnaires were discarded and the remaining were incorporated in the study. Final data of hundred cases was obtained at the end which was then analyzed using regression and correlation statistics.

\section{Results}

Table 1

Regression analysis of Social Media Preferences and Social Media Marketing Predicting Consumer Buying Behavior

\begin{tabular}{|c|c|c|c|c|}
\hline Model & $\mathrm{R}$ & R Square ${ }^{b}$ & $\begin{array}{l}\text { Adjusted R } \\
\text { Square }\end{array}$ & $\begin{array}{l}\text { Std. Error of } \\
\text { the Estimate }\end{array}$ \\
\hline 1 & $0.98^{\mathrm{a}}$ & 0.97 & 0.97 & 0.43 \\
\hline $\begin{array}{ll}\text { a. } & \operatorname{Pr} \\
& \operatorname{Pr}\end{array}$ & $\begin{array}{l}\text { Social } \\
\text { es Mean }\end{array}$ & Media Mar & eting Mean, & Social Medi \\
\hline
\end{tabular}

In table $1 \mathrm{R}$ is called a measure of how well our independent variables predict the results. $\mathrm{R}$ is used to clarify the association between variables selected for the study. R2 makes clear overall variation in the predictant and its value is 0 to 1 . In the study R2 value .974 which signifies a good fit between the model and the population. More accurately it can be claimed that both of the independent variables of the current study have significantly impacted the consumer buying behavior by $97.4 \%$. 
Table 2

Pearson's Correlation of Social Media Marketing, Social Media Preferences and Consumer Buying Behavior.

\begin{tabular}{|c|c|c|c|c|}
\hline & & 1 & 2 & 3 \\
\hline 1 & CBB & - & & \\
\hline 2 & SMP & $.33 * *$ & - & \\
\hline 3 & SMM & $.64 * *$ & $.29 * *$ & - \\
\hline
\end{tabular}

Table 2 shows that there is significant positive correlation among all the variables selected for the current study. It can be concluded that an increase in a variable is associated with an increase in other variable. Following results obtained by person's correlation analysis are given: CBB and SMP are positive and significant, while looking for association of dependent variable, consumer buying behavior, with independent variable social media preference there is positive and significant association which is .33 which is significant. CBB and SMM positive and significant, while looking for association of dependent variable, consumer buying behavior, with independent variable social media marketing there is positive and significant association which is .64 which is significant.

SMM and SMP are positively and significantly correlated, similarly the association between social media marketing and social media preference there is positive and significant. The correlation value is .29 which is significant at $\mathrm{p}<.01$. It can be concluded that consumer buying behavior has a significant positive correlation with social media preference and social media marketing.

\section{Discussion}

The major objective of the present study was to find out the effect of social media marketing on consumer buying behavior. It was hypothesized that social media marketing and social media preferences will have a significant impact on consumer buying behavior. Regression analysis and Pearson product moment correlation coefficient were used to study this hypothesis. Results showed that social media marketing and social media preferences significantly predicted consumer buying behavior. Weinberg (2009) found that social media is the best way for promoting products and taking advantage of a diverse population. 
The social media or web 2.0 it has become a fact of life for the new generation of people it in sewn into the fabric of reality of all that belong to the age of information and technology and it is growing without showing any sign of slowing down. It has opened many opportunities for business whether they may be corporations, privately owned or small and medium business they have provided them access to both current clients and specially potential clients to be interacted with on personal bases and be able to directly address any issues, questions or request that they may have without confining them to traditional questions and giving them complete freedom to express their opinion and interact with the business entity. It is clear through past research that social media plays an important role in consumer's decision taking for the purchase of different market products.(Lee,2013).Current research studied and investigated the relationship between social media marketing and consumer buying behavior in Peshawar and this study has concluded with the backing of empirical data that there is a positive relationship between social media marketing and consumer buying behavior.

Electronic media plays an important role in fulfilling people's needs and this is done through social media marketing (Isra, Elham \& Sara 2015) .

\section{Implications}

Present research has very significant implications in the area of business and marketing. Past research in the area of social media marketing has proved that marketers giving more time to social media enhanced their benefits in different sales areas (Micheal,2014).The findings of this research has also provided the businessmen as well as future researchers an insight into the role of social media marketing in consumers buying behavior. It has been proven that people of this region use social media in order to find information and form opinion about variety of things in which services and products of companies and brands are included. Meaning social media is a very effective medium to interact with the people of Peshawar. 


\section{References}

Dann, S. \& Dann. S. (2011). E-Marketing: Theory and Application. London, U.K: Palgrave Macmillan.

Drury, G.n. (2008). Social Media: Should marketers engage and how can it be done effectively". Journal of Direct, Data and Digital Marketing Practice 9 (3): 274-277. USA: Palgrave Macmillan.

Fennin, B. M., \& Stroebe. (2010). The Psychology of Advertising. Philippines: Psychology Press.

Isra A. D., Elham A. M. \& Sara I. (2015). The Impact of Social Media on Consumer Buying Behaviour, Special Topics in Information Systems, 1-12.

Kaplan, Andeas M. and Haenlein, Michael (2010). Users of the World, Unite! The Challenges and Opportunities of Social Media. Business Horizons 53, 59-68.

Lee,E.,(2013).Imact of Social Media on Consumer Behavior -Decision Making Process. Unpublished Bechlor's Thesis. Finland: Turkey University of Applied Sciences.

Marketing Profs. (2012). B2B Content Marketing: Trends and Benchmarks for 2012. (http://www.marketingprofs.com/charts/2012/9055/b2bcontent-marketing-trends-and-benchmarks-for-2012 [Accessed on January 18, 2016]).

Mayfield, A. (2008). What is Social Media. U.K: An e-book from iCrossing.

Mckinsey (May 2011) Global Institute Report on Big data: The next frontier for innovation, competition and productivity for innovation, competition and productivity, New York.

Michael, A. S.,(2014).How Marketers are using social media to grow their Bussiness. Social Media Marketing Industry Report. Published by Social Media Examiner.

O'Reilly, T. (2006). Web 2.0 Compact Definition: Trying Again.(http://radar.oreilly.com/2006/12/web-20-compact-definitiontryi.html accessed on (February 15, 2016).

Safko, L. \& Brake, D. K. (2009). The Social Media Bible. Tactics, Tools and Strategies for business Success. N.J, USA: John Wiley and Sons

Silverman, G. (2001). The Secrets of Word-of-Mouth Marketing. USA: AMACOM.

PESHAWAR JOURNAL OF PSYCHOLOGY AND BEHAVIORAL SCIENCES, 2018, VOL. 4, NO. 2, 193-202 
Smith, PR \& Zook, Z. (2011). Marketing Communications: Integrating Offline and Online with Social Media. Fifth Edition. London, U.K: Kogan Page Ltd.

Solis, B. (2010). Defining Social Media:2006 - 2010. http://www.briansolis.com/2010/01/defining-social-media-the-sagacontinues/ [Accessed on January 10, 2016]).

Solis,B. (2007). The Social Media Manifesto. (http://www.briansolis.com/2007/06/future-of-communicationsmanifesto-for/ [Accessed on January 16, 2016]).

Weber, L. (2009). Marketing to the Social Web: How digital customer communities build your business. Second Edition. N.J, USA: John Wiley and Sons.

Weinberg, T. (2009). The New Community Rules: Marketing on the Social Web. Sebastopol, CA: O'Reilly Media Inc.

Young Entrepreneur Council. (2012). 5 Ways Social Media Takes Customer Relationships ToThe Next Level.

(http://www.forbes.com/sites/theyec/2012/12/24/5-ways-socialmedia-takes-customer-relationships-to-the-next-level-2/ [Accessed on January 16, 2016]).

Zarrella, D. (2010). The Social Media Marketing Book. Sebastopol, CA: O’Reilly Media Inc. 